Masayuki Matsumoto - Seiji Hayasaka - Yoshihiro Hotta

Keiko Fujiki • Takuro Fujimaki • Misako Takeda

Nobuo Ishida - Shin-ichiro Endo - Atsushi Kanai

\title{
Mitochondrial DNA mutations in Japanese patients with optic neuropathy unassociated with a mutation at nucleotide position 11,778
}

Received: March 10, 1997 / Accepted: October 22, 1997

\begin{abstract}
We examined for mitochondrial DNA (mtDNA) mutations at nucleotide positions(nt) 3460, 14,484, 9438, 9804, and 15,257 in ten Japanese patients with idiopathic optic neuropathy unassociated with a mutation at nt11,778. The mtDNAs were amplified by polymerase chain reaction (PCR), the products were digested with restriction enzymes, and the sizes of the fragments were analyzed on $8 \%$ polyacrylamide gel. Of the ten patients, one had an mtDNA mutation at nt3460 and another patient had a mutation at nt14,484. We suggest that mtDNA mutations in Japanese patients with optic neuropathy unassociated with a mutation at nt11,778 should be further investigated.
\end{abstract}

Key words Leber hereditary optic neuropathy · nt3460 mutation · nt14,484 mutation · Optic neuropathy · Japanese patients

\section{Introduction}

Leber hereditary optic neuropathy (LHON) is a maternally inherited disease characterized by acute visual impairment in both eyes. The disease is associated with 17 missense mutations in mitochondrial DNA (mtDNA) (McKusick 1994). Of the 17 mutations, 3 are thought to be primary, and the presence of these three greatly increases the possibility of blindness (Brown et al. 1997). Mutations in mtDNA have been commonly reported at mucleotide positions (nt) 11,778, 3460, 14,484, 9438, 9804, and 15,257 (Wallace et al.

M. Matsumoto $(\bowtie) \cdot S$. Hayasaka

Department of Ophthalmology, Toyama Medical and

Pharmaceutical University, 2630 Sugitani, Toyama 930-01, Japan

Tel. +81-764-34-2281; Fax +81-764-36-0146

e-mail: g5410105@ms.toyama-mpu.ac.jp

Y. Hotta $\cdot$ K. Fujiki $\cdot$ T. Fujimaki $\cdot$ M. Takeda $\cdot$ A. Kanai Department of Ophthalmology, Juntendo University School of Medicine, Tokyo, Japan

N. Ishida $\cdot$ S. Endo

Ishida Eye Hospital, Niigata, Japan
1988; Fujiki et al. 1991; Huoponen et al. 1991; Majander et al. 1991; Johns et al. 1992a and 1992b; Johns and Neufeld 1993; Mashima et al. 1993; Newman 1993; Nakamura et al. 1994; Oostra et al. 1994; Hotta et al. 1995; Riordan-Eva et al. 1995; Fujimaki et al. 1996; Ghosh et al. 1996; Joo et al. 1996; Nikoskelainen et al. 1996). A high frequency of mtDNA mutations at nt11,778 has been reported in Japanese patients with the disease (Fujiki et al. 1991; Mashima et al. 1993; Hotta et al. 1995). In an earlier study, we examined for the nt11,778 mutation in 39 Japanese patients with idiopathic optic neuropathy, and reported clinical features in 29 LHON patients with the nt11,778 mutation (Fujimaki et al. 1996). In the present study, we examined for mtDNA mutations at nt3460, 14,484, 9438, 9804, and 15,257 in the 10 Japanese patients with idiopathic optic neuropathy unassociated with the nt11,778 mutation in that earlier study.

\section{Subjects and methods}

In an earlier study (Fujimaki et al. 1996), we examined for the nt11,778 mutation in mtDNA in 39 individuals with idiopathic optic neuropathy who were patients at the Eye Clinic of Juntendo University Hospital from 1989 to 1995. Twenty-nine of the 39 patients had the nt11,778 mutation. In the present study, we examined the 10 remaining patients whose idiopathic optic neuropathy was unassociated with the nt11,778 mutation. Informed consent for the present study was obtained from each patient.

mtDNA was extracted from cells of peripheral blood samples. We used five pairs of primers to determine nt3460, $14,484,9438,9804$, and 15,257 mutations (Table 1). The DNA fragments were amplified by PCR, using a DNA Thermal Cycler (Perkin-Elmer Cetus, Branchburg, NJ, USA). The purified PCR products were digested with restriction enzymes (New England Bio Labs, Beverly, MA, USA and Boehringer Mannheim, Mannheim, Germany) (Table 1), and the sizes of the fragments were determined on $8 \%$ polyacrylamide gel containing ethidium bromide. 
Table 1 Polymerase chain reaction primers for mtDNA mutations

\begin{tabular}{|c|c|c|}
\hline Nucleotide position & Primers & Restriction enzyme \\
\hline 11,778 ( $\mathrm{G}$ to $\mathrm{A})$ & $\begin{array}{l}\text { Sense: ATACTCTTCAATCAGCCACATAGC } \\
\text { Antisense: GAGAACGTGGTTACTAGCACAGAG }\end{array}$ & SfaN I and Mae III \\
\hline 3460 & $\begin{array}{l}\text { Sense: CACACCCACCCAAGAACAGGG } \\
\text { Antisense: GAGATTGTTTGGGCTACTGC }\end{array}$ & $H g a \mathrm{I}$ \\
\hline 14,484 & $\begin{array}{l}\text { Sense: AGTATATCCAAAGACAACGA }{ }^{\mathrm{a}} \\
\text { Antisense: GATGTATGCTTTGTTTCTGT }\end{array}$ & Sau3A I \\
\hline 9438 & $\begin{array}{l}\text { Sense: ATCCAAGCCTACGTTTTC } \\
\text { Antisense: GATGAAGCAGATAGTGAG }\end{array}$ & Stu I \\
\hline $9804(\mathrm{G}$ to $\mathrm{A})$ & $\begin{array}{l}\text { Sense: ATCCAAGCCTACGTTTTC } \\
\text { ANtisense: GATGAAGCAGATAGTGAG }\end{array}$ & Mae III \\
\hline 15,257 & $\begin{array}{l}\text { Sense: CTCCTGCTTGCAACTAT } \\
\text { Antisense: CCGAGGGCGTCTTTGAT }\end{array}$ & $A c c \mathrm{I}$ \\
\hline
\end{tabular}

mt DNA, Mitochordrial DNA

${ }^{\text {a }}$ The underline indicates a mismatched nucleotide

Table 2 Clinical features and mtDNA mutations in patients with optic neuropathy

\begin{tabular}{|c|c|c|c|c|c|c|c|c|c|c|c|c|c|}
\hline \multirow{3}{*}{$\begin{array}{l}\text { Patient } \\
\text { no. }\end{array}$} & \multirow{3}{*}{$\begin{array}{l}\text { Age at } \\
\text { onset } \\
\text { (years) }\end{array}$} & \multirow[b]{3}{*}{ Sex } & \multirow{3}{*}{$\begin{array}{l}\text { Family } \\
\text { history }\end{array}$} & \multicolumn{4}{|c|}{ Findings at initial visit } & & & & & & \\
\hline & & & & \multicolumn{2}{|c|}{ Visual acuity } & \multicolumn{2}{|c|}{ Optic disc } & \multicolumn{6}{|c|}{ mtDNA mutations } \\
\hline & & & & $\mathrm{OD}$ & OS & $\mathrm{OD}$ & OS & 11,778 & 3460 & 14,484 & 9438 & 9804 & 15,257 \\
\hline 1 & 19 & M & + & 0.08 & 0.02 & $\mathrm{P}$ & $\mathrm{P}$ & - & - & - & - & - & - \\
\hline 2 & 17 & $\mathrm{~F}$ & - & 0.4 & 0.7 & $\mathrm{P}$ & $\mathrm{P}$ & - & + & - & - & - & - \\
\hline 3 & 20 & $\mathrm{M}$ & - & 0.09 & 0.06 & $\mathrm{P}$ & $\mathrm{P}$ & - & - & + & - & - & - \\
\hline 4 & 39 & $\mathrm{M}$ & - & 0.04 & 1.0 & $\mathrm{~S}$ & $\mathrm{~N}$ & - & - & - & - & - & - \\
\hline 5 & 10 & M & - & 0.3 & 0.2 & $\mathrm{P}$ & $\mathrm{P}$ & - & - & - & - & - & - \\
\hline 6 & 37 & $\mathrm{M}$ & - & 0.15 & 0.1 & $\mathrm{P}$ & $\mathrm{P}$ & - & - & - & - & - & - \\
\hline 7 & 12 & $\mathrm{M}$ & - & $\mathrm{CF}$ & 1.0 & $\mathrm{~S}$ & $\mathrm{~N}$ & - & - & - & - & - & - \\
\hline 8 & 17 & M & - & 0.08 & 0.08 & $\mathrm{P}$ & $\mathrm{P}$ & - & - & - & - & - & - \\
\hline 9 & 13 & $\mathrm{M}$ & - & 0.5 & 0.5 & $\mathrm{P}$ & $\mathrm{P}$ & - & - & - & - & - & - \\
\hline 10 & 19 & M & - & 0.1 & HM & $\mathrm{P}$ & $\mathrm{P}$ & - & - & - & - & - & - \\
\hline
\end{tabular}

CF, Counting fingers; HM, hand motion; $\mathrm{P}$, pallor; S, swelling; N, normal; +; positive; -, negative; OD, right eye; OS, left eye

\section{Results}

The clinical features and mtDNA mutations in the ten patients with optic neuropathy are shown in Table 2. Eight patients had bilateral optic disc pallor and two had unilateral optic disc swelling. Patient 1 had a family history of optic atrophy: his maternal uncle had bilateral optic atrophy. This patient, however, had no mutation at either nt11,778, 3460, 14,484, 9438, 9804, or 15,257. Patient 2 was diagnosed with bilateral optic atrophy at age 17 years. She had relatively good visual acuity in both eyes (0.4 OD and $0.7 \mathrm{OS}$ ). She had no family history of optic neuropathy, but she had an mtDNA mutation at nt3460 (Fig. 1). Patient 3 was diagnosed with bilateral optic atrophy at age 20 years. He had poor visual acuity in both eyes (0.09 OD and 0.06 OS). He had no family history of optic neuropathy, but he had a mutation at nt14,484 (Fig. 2). Patients 4-10 had no family history of optic neuropathy and no mutations at nt11,778, 3460, 14,484, 9438, 9804, or 15,257.

\section{Discussion}

In our previous study of 39 patients with LHON and with possible hereditary optic neuropathy, we found that 29 had an mtDNA nt11,778 mutation (Fujimaki et al. 1996). In the present study of the remaining 10 patients in whom the optic neuropathy was unassociated with the nt11,778 mutation, patient 2 had an mtDNA mutation at nt3460, and patient 3 had an mtDNA mutation at nt14,484.

Nakamura et al. (1994), Hiida et al. (1995), and Joo et al. (1996) reported an nt3460 mutation in Japanese patients with LHON and suggested that the prevalence of the mutation in Japanese patients may be lower than that in patients of other ethnic origins. However, it is likely that the prevalence of the nt3460 mutation in Japanese patients with LHON may be higher than previously thought, in the light of our finding of one patient with this mutation in the present screening of a small number of patients with idiopathic optic neuropathy. Patients with LHON and the nt3460 mutation are thought to have better visual function than those with the nt11,778 mutation (Johns et al. 1992b; Joo et al. 1996; Nakamura et al. 1994; Newman 1993; Nikoskelainen et al. 1996). Patient 2 in the present study also had relatively good visual acuity in both eyes. We were unable to examine for the mutation in her asymptomatic maternal relatives. Majander and co-workers (1991) reported that nicotinamide adenine dinucleotide, reduced (NADH): ubiquinone reductase had different electron transfer properties in the NADHdehydrogenase subunit 1 


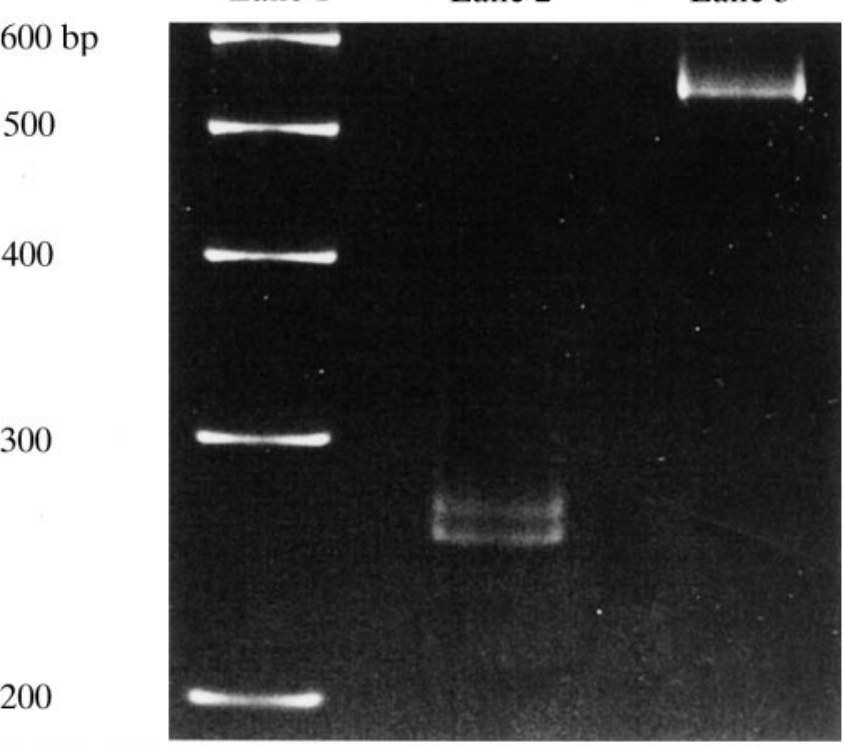

Fig. 1 Analysis of mutation at nucleotide position (nt)3460 of mitochordrial (mt)DNA. Shown is $8 \%$ polyacrylamide gel electrophoresis after $\mathrm{Hga}$ I digestion of polymerase chain reaction (PCR) products encompassing nt3460. Lanes 1,2, and 3 represent size marker, normal control, and patient 2 sample, respectively. Numbers at left indicate base-pair lengths of corresponding bands. Note that lane 2 has two visible bands, of 254 and 268 base-pair lengths, by $\mathrm{Hga}$ I digestion. Lane 3 exhibits only a 522-base pair length band, due to loss of the enzyme's recognition site, demonstrating a mutated sequence in this region

\section{Lane 1 Lane $2 \quad$ Lane 3}

$300 \mathrm{bp}$

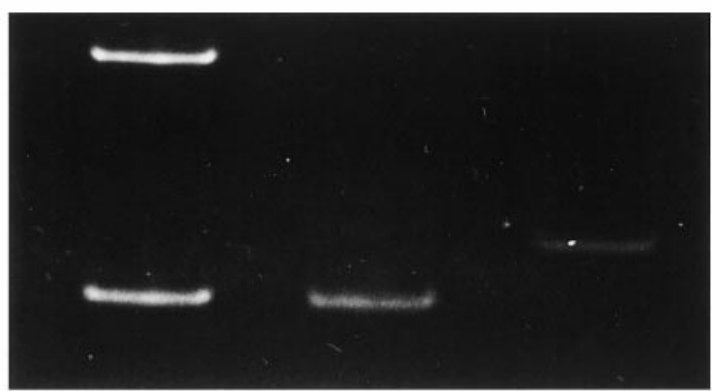

Fig. 2 Analysis of mtDNA mutation at nt14,484. Shown is $8 \%$ polyacrylamide gel electrophoresis after Sau3A I digestion of PCR products encompassing nt14,484. Lanes 1,2, and 3 represent size marker, normal control, and patient 3 sample, respectively. Numbers at left indicate base-pair lengths of corresponding bands. Note that lane 2 has a band of 190-base pair length by Sau3A I digestion. Lane 3 exhibits a 208-base pair length band, due to loss of recognition site of Sau3A I, demonstrating a mutated sequence in this region

(ND1)/3460 and the ND4/11,778 mutations of LHON. These different biochemical properties may result in different clinical features.

Johns et al. (1992b), Oostra et al. (1994), and RiordanEva et al. (1995) reported an mtDNA mutation at nt14,484 in patients with LHON. Riordan-Eva et al. (1995) showed that good visual outcome was strongly correlated with age at onset in the patients with the nt14,484 mutation; in all those whose onset was before age 20 years, final visual acuity was better than 6/24. Patient 3 in the present study developed optic neuropathy at age 20 years. Although Yamada et al. (1997) indicated that patients with the nt14,484 mutation had good visual outcome, our patient 3 had poor visual acuity. We were not able to examine for the mutation in his asymptomatic maternal relatives.

We suggest that mtDNA mutations in patients with idiopathic optic neuropathy unassociated with the nt11,778 mutation should be further investigated to enable precise diagnosis and appropriate genetic counseling.

\section{References}

Brown MD, Sun F, Wallace DC (1997) Clustering of Caucasian Leber hereditary optic neuropathy patients containing the 11,778 or 14,484 mutations on an mtDNA lineage. Am J Hum Genet 60: 381-387

Fujiki K, Hotta Y, Hayakawa M, Saito K, Ara F, Ueda S, Goto T, Ishida M, Yanashima K, Shiono T, Sakai J, Kanai A, Nakajima A (1991) A mutation of mitochondrial DNA in Japanese families with Leber's hereditary optic neuropathy. Jpn J Human Genet 36: 141145

Fujimaki T, Hotta Y, Hayakawa M, Yokoyama T, Takeda M, Hayatsu H, Toshida H, Tamaki K, Ishida N, Ueda S, Fujiki K, Kanai A (1996) DNA diagnosis and clinical features of hereditary optic neuropathy of Leber. Jpn J Clin Ophthalmol (Rinsho Ganka) 50: 1179-1182

Ghosh SS, Fahy E, Bodis-Wollner I, Sherman J, Howell N (1996) Longitudinal study of a heteroplasmic 3460 Leber hereditary optic neuropathy family by multiplexed primer-extension analysis and nucleotide sequencing. Am J Hum Genet 58: 325-334

Hiida Y, Mashima Y, Saga M, Shuu M, Akiya S, Kudo J, Shimizu N, Oguchi Y (1995) Molecular genetic analysis of Leber's hereditary optic neuropathy with the 3460 mutation in Japanese pedigrees. J Jpn Ophthalmol Soc 99: 728-734

Hotta Y, Fujiki K, Hayakawa M, Nakajima A, Kanai A, Mashima Y, Hiida Y, Shinoda K, Yamada K, Oguchi Y, Ishida M, Yamashima K, Wakakura M, Ishikawa S, Nakamura M, Sakai J, Yamamoto M, Hayashi T, Mitani I, Miyazaki S, Shimo-oku M, Imachi J, Kuniyoshi N, Nagataki S, Isashiki Y, Ohba N (1995) Clinical features of Japanese Leber's hereditary optic neuropathy with 11,778 mutation of mitochondrial DNA. Jpn J Ophthalmol 39: 96-108

Huoponen K, Vilkki J, Aula P, Nikoskelainen EK, Savontaus ML (1991) A new mtDNA mutation associated with Leber hereditary optic neuroretinopathy. Am J Hum Genet 48: 1147-1153

Johns DR, Smith KH, Miller NR (1992a) Leber's hereditary optic neuropathy. Clinical manifestations of the 3460 mutation. Arch Ophthalmol 110: 1577-1581

Johns DR, Neufeld MJ, Park RD (1992b) An ND-6 mitochondrial DNA mutation associated with Leber's hereditary optic neuropathy. Biochem Biophys Res Commun 187: 1551-1557

Johns DR, Neufeld MJ (1993) Cytochrome $c$ oxidase mutations in Leber hereditary optic neuropathy. Biochem Biophys Res Commun 196: 810-815

Joo JH, Takahashi H, Furukawa H, Akiya S, Hiida Y, Mashima Y (1996) Visual recovery in a case of hereditary optic neuropathy of Leber with 3460 mutation. Jpn J Clin Ophthalmol (Rinsho Ganka) 50: 487-490

Majander A, Huoponen K, Savontaus ML, Nikoskelainen E, Wistrom M (1991) Electron transfer properties of NADH: Ubiquinone reductase in the ND1/3460 and the ND4/11,778 mutations of the Leber hereditary optic neuropathy (LHON). FEBS Lett 292: 289292

Mashima Y, Hiida Y, Oguchi Y, Kudoh J, Shimizu N (1993) High frequency of mutations at position 11,778 in mitochondrial ND4 gene in Japanese families with Leber's hereditary optic neuropathy. Hum Genet 92: 101-102

McKusick VA (1994) Leber optic atrophy. In: McKusick VA (ed) Mendelian Inheritance in man. Johns Hopkins University Press, Baltimore, pp 2587-2592 
Nakamura M, Tanigawa M, Yamamoto M (1994) A case of Leber's hereditary optic neuropathy with mitochondrial DNA mutation at nucleotide position 3460. Jpn J Ophthalmol 38: 267-271

Newman NJ (1993) Leber's hereditary optic neuropathy: New genetic considerations. Arch Neurol 50: 540-548

Nikoskelainen EK, Huoponen K, Juvonen V, Lamminen T, Nummelin K, Savontaus ML (1996) Ophthalmologic findings in Leber hereditary optic neuropathy, with special reference to mtDNA mutations. Ophthalmology 103: 504-514

Oostra RJ, Bolhuis PA, Wijburg FA, Zorn-Ende G, BleekerWagemarkers EM (1994) Leber's hereditary optic neuropathy: Correlations between mitochondrial genotype and visual outcome. J Med Genet 31: 280-286
Riordan-Eva P, Sanders MD, Govan GG, Sweeney MG, Da Costa J, Harding AE (1995) The clinical features of Leber's hereditary optic neuropathy defined by the presence of a pathogenic mitochondrial DNA mutation. Brain 118: 319-337

Wallace DC, Singh G, Lott MT, Hodge JA, Schurr TG, Lezza AMS, Elsas LJ II, Nikoskelainen EK (1988) Mitochondrial DNA mutation associated with Leber's hereditary optic neuropathy. Science 242: $1427-1430$

Yamada K, Mashima Y, Kigasawa K, Miyashita K, Wakakura M, Oguchi Y (1997) High incidence of visual recovery among four Japanese patients with Leber's hereditary optic neuropathy with the 14,484 mutation. J Neuro-Ophthalmol 17: 103-107 